doi: 10.32620/oikit.2021.92.05

УДК 629.7

О. М. Застела

\title{
Моделювання процесу штампування опуклого кутника згинанням-формуванням передавальним середовищем
}

\author{
Національний аерокосмічний університет ім. М. Є. Жуковського \\ "Харківський авіаційний інститут»
}

\begin{abstract}
Комп'ютерне моделювання дозволяє слідкувати за навантаженням матеріалу та його поведінкою в ході формозміни, визначати енергосилові параметри процесу, відображати кінематику руху інструмента, передавального серевища та самої заготовки. Це забезпечує загалом значне скорочення часу і витрат на проведення натуральних експериментів, в цілому значне зменшення обсягів технологічної підготовки штампувальних робіт. Указаний метод найбільш підходить для удосконалення сучасного штампувального виробництва 3 використанням передавальних середовищ. Для проведення чисельних експериментів в області штампування заготовок з листа найбільш прийнятними є варіаційний метод або МСЕ. Такий підхід забезпечує мінімальну розбіжність між результатами натуральних та чисельних експериментів. МСE широко використовується в різних програмних продуктах - Nastran, Ansys, Katy та інших, що дозволяє оптимізувати процес отримання даних скороченням часу розрахунку, швидко корегувати на всілякі зміни умов деформування. Під час формоутворення опуклого кутника відбуваються значні зміни геометрії, пов'язані 3 гофроутворенням на відбортованій частині заготовки. 3 цієї причини підходи до утворення дискретизації сітки для розрахунків МСЕ мають особливості прийомів використання у величинах елементів розбивання, зокрема для передавального середовища та самої листової заготовки розміри елементів малі, а для оснащення можуть вибиратися великими, окрім поверхні згинання. Побудова математичної моделі на основі МСЕ дозволяє не лише визначити необхідні параметри процесу, але і розглянути процес формозміни на окремих його стадіях, визначити картину напружено-деформованого стану, виявити найбільш небезпечні зони згинанням-штампуванням, зміну товщини матеріалу, а також простежити поведінку матеріалу після розвантаження. Все це дає змогу оцінити якість отримуваного виробу за визначеними параметрами процесу, а також одержати бажані результати шляхом варіювання початкових параметрів моделі.
\end{abstract}

Ключові слова: моделювання процесу штампування борта, листова заготовка, опуклий кутник, згинання-формування, передавальне середовище.

Одним з найбільш поширених у штампувальних технологічних процесах $€$ штампування згинанням-фрормуванням. Раніше в роботі [1] показано, що відмінною особливістю процесу згинання-фрормування $€$ вільна взаємодія інструмента (еластичне середовище) з плоскою заготовкою у вигляді полоси, що спирається на абсолютно жорстку опору, інструмент, що є носієм фрорми деталі. Вільне згинання-формування еластичним середовищем має великі технологічні можливості і граничну простоту змінного інструмента. Якість поверхні отриманої деталі, як і в інших видах штампування, залежить від чистоти оброблення поверхні інструмента.

Плоска заготовка стає під дією зусиль з боку пуансона і еластичної матриці просторово зігнутою деталлю. До основних параметрів процесу згинання еластичним середовищем належать зусилля деформації, потрібний 
деформувальний тиск, глибина згинання, необхідна твердість і міцність поліуретану, а також параметри, що визначають точність процесу.

Розвязки задач з визначення основних параметрів процесу штампування потребують максимально можливої лінеаризації фрізико-механічних процесів і геометричних граничних умов, використання поетапного розв'язування. Проте прийняті допущення не мають істотно спотворювати дійсну фрізику процесу. Для оцінювання рівня відповідності модельного процесу натурному необхідно потім провести порівняння результатів із заздалегідь вибраними критеріями.

При побудові математичної моделі операції згинання-фрормування еластичним середовищем на жорсткій матриці були використані такі припущення: тиск 3 боку еластичного середовища на заготовку $\epsilon$ гідростатичним; напруження за нормаллю до товщини оболонки (через їх малість порівняно з напруженням, що діє в площині листа) приймається таким, що дорівнює нулю, через малість відносної товщини стінки формованої деталі.

Внаслідок малості деформацій елементів оснащення (матриці) порівняно 3 деформаціями заготовки 3 метою спрощення розрахунку і скорочення машинного часу деформаціями елементів оснащення можна нехтувати. У зв'язку з цим матрицю приймають абсолютно твердим тілом. Механічні параметри матеріалу заготовки визначають за білінійним законом зміцнення, теплові ефекти не враховують.

При реалізації математичної моделі була створена і відлагоджена програма для ПЕВМ, що дозволяє методом послідовних наближень визначити НДС фрормованої заготовки на кожному кроці навантаження аж до моменту появи однієї з можливих (на цій операції) технологічних відмов деформаційного типу.

На основі безмоментної теорії тонкостінних оболонок розроблено математичну модель операції штампування деталей 3 листа еластичним середовищем по жорсткій матриці. Для реалізації такої моделі в системі комп'ютерного моделювання складено алгоритм і програму розрахунку НДС формованої заготовки.

Застосування пропонованої математичної моделі дає змогу не лише проектувати операції згинання-формування еластичним середовищем, але і вирішувати завдання, пов'язані з ії оптимізацією. Крім того, створюються

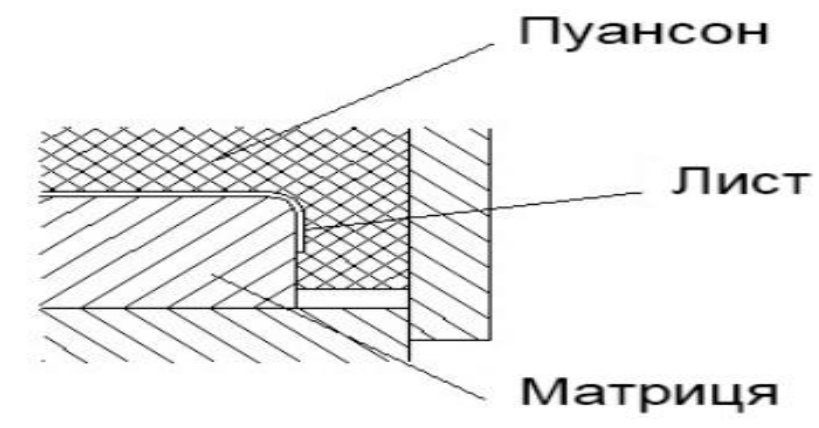

Рис. 1 - Схема при формуванні випуклого борта. передумови для оцінювання технологічності деталі, що виготовляється, ще на стадії проектування конструкції.

Для дослідження було вибрано деталь типу кутника 3 опуклим бортом. У процесі штампування для отримання остаточної форми деталі здійснюють згинання борту. Схему процесу дії сил для згинання показано на рисунку 1. Вирішення завдань аналогічно роботі [1] проводять у два етапи, в першому буде здійснено безпосереднє формоутворення, а в другому розглянуто залишкові явища 
процесу, в даному випадку - пружинення. Таке розмежування пов'язано із специфікою MCE системи ANSYS/LS - DYNA [2]. Це обумовлено істотною фрізичною і геометричною нелінійністю процесу згинання-формування, що характеризується протяжними контактними поверхнями і значними пластичними деформаціями. Як матеріал для заготовки було вибрано матеріал Д16АМ. Необхідні для вирішення завдання фрізико-механічні властивості наведено в таблиці 1.

Значення фрізико-механічних параметрів матеріалу заготовки. Таблиця 1

\begin{tabular}{|c|c|c|c|c|}
\hline $\begin{array}{c}\text { Коесріцієнт } \\
\text { Пуассона } \mu\end{array}$ & $\begin{array}{c}\text { Межа } \\
\text { плинності } \\
\sigma_{T}, \text { МПа }\end{array}$ & $\begin{array}{c}\text { Модуль } \\
\text { гнучкості E, } \\
\text { МПа }\end{array}$ & $\begin{array}{c}\text { Модуль } \\
\text { зміцнення П, } \\
\text { МПа }\end{array}$ & $\begin{array}{c}\text { Питома вага } \rho, \\
\text { кг/м }{ }^{3}\end{array}$ \\
\hline 0,34 & 108 & 72000 & 480 & 2750 \\
\hline
\end{tabular}

Матеріал матриці - сталь 20 має такі характеристики: $\sigma_{T}=236 \mathrm{MПа;}$

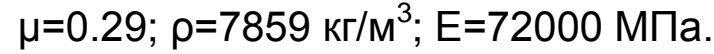

Для пуансона як матеріал для еластичного середовища вибрано поліуретан СКУ-7Л з густиною $\rho=1250$ кг $/ \mathrm{m}^{3}$ та модулем при розтягуванні $300 \%$, що дорівнює 7 МПа.

Алгоритм згинання-фрормування борту опуклого кутника 3 деталі показано на рисунку 2.

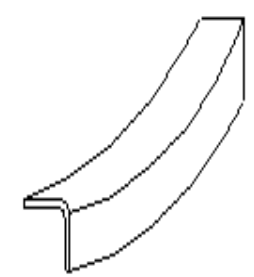

Рис. 2. Ескіз деталі

Деталь виготовляється 3 матеріалу Д16АМ з товщиною листа 1,2 мм. Геометричні параметри системи для деталі наведено в таблиці 2.

Геометричні параметри системи для випуклого кутника Таблиця 2

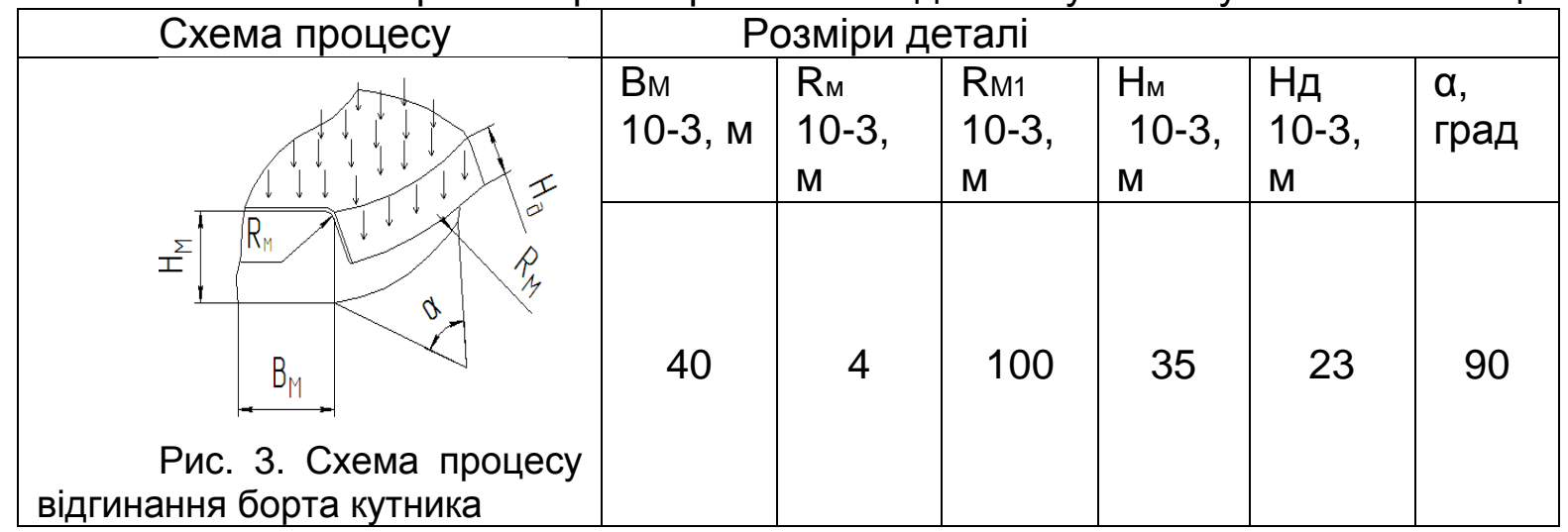

Примітка. Вм -ширина матриці; Rм1 - радіус округлення робочої крайки матриці; Rм - радіус матриці в увігнутій частині; $\mathrm{H}_{\mathrm{M}}$ - висота матриці; $\alpha$ - кут 
опуклої частини матриці; Нд - висота борту, що відгинається.

Етапи моделювання процесу подібні до етапів моделювання діафрагми, тому при описі будуть розглянуті тільки ті моменти, в яких існують відмінності в процесах.

1. Завдання: визначення напружено-деформованого стану деталі і енергосилових параметрів процесу.

2. Побудова геометричної моделі. Проводиться за принципом зверху вниз, від побудови об'ємів деталей до побудови поверхонь методом видалення. Поліуретановий пуансон в даному випадку повторює фрорму деталі, Щ зроблено з метою спрощення завдання і збереження часу машинного розрахунку.

3 - 5. Дискретизація простору (створення сітки), аналогічні попередньому алгоритму. Оскільки це завдання порівняно з попереднім $€$ складнішим, то поверхні як еластичної подушки, так і заготовки розбивають на досить дрібні елементи. Меширування матриці як і раніше можна робити великими елементами, окрім поверхні згинання. Кінцеве меширування показане на рисунку 4.

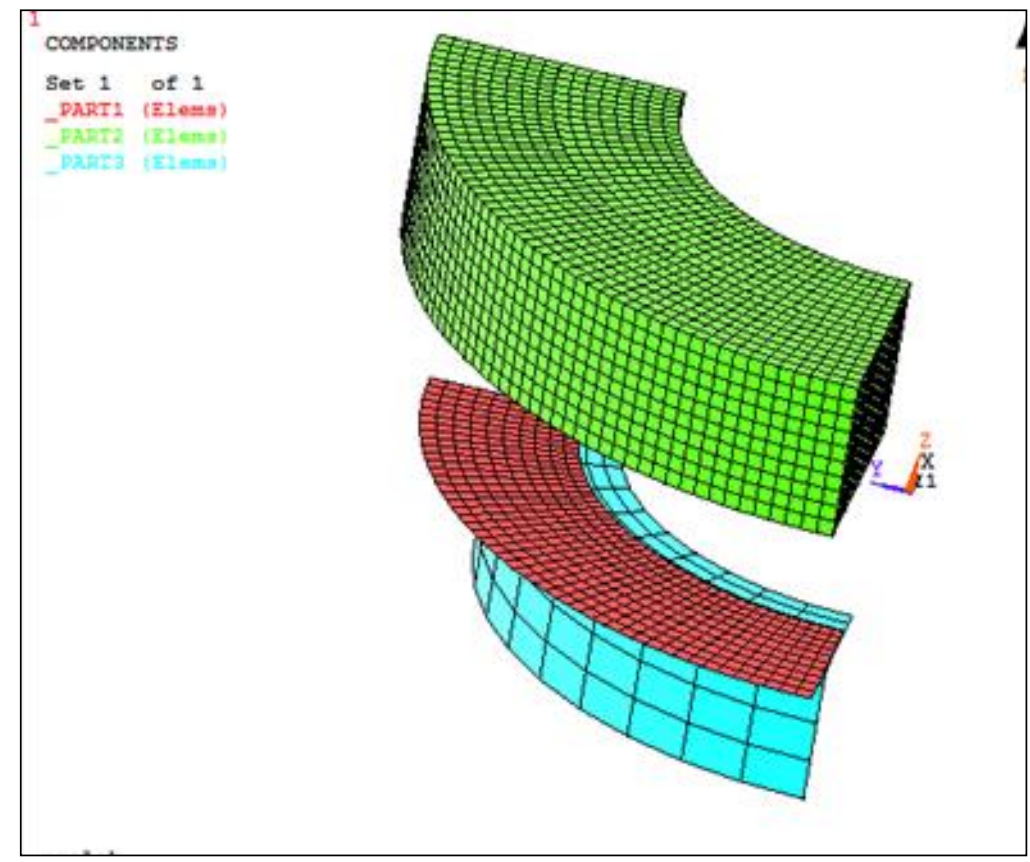

Рис. 4. Модель меширування (дискредитації)

До початку процесу пуансон заздалегідь опускається на мінімальну висоту, після проходження якої вже відбувається зіткнення.

6. Завдання граничних умов симетрії. Для пуансона $\epsilon$ аналогічним попередньому алгоритму. У заготовці забороняються пересування тих вузлів, які лежать на поверхні матриці до лінії згинання.

7. Завдання контактних умов аналогічно першому алгоритму.

8. Додаток навантажень в цьому завданні використовується як зовнішнє кінематичне навантаження (рух пуансона з певною швидкістю).

9. Перегляд результатів розрахунку. В цьому завданні особливий інтерес становитть розгляд формоутворення покроково, оскільки відбуваються значні зміни геометрії деталі, пов'язані з гофроутворенням на відтбортованій частині заготовки. На рисунку 5 показано розподіли напруження на кінцевій стадії 
формоутворення. На початковій стадії формоутворення відбувається тільки вигин і максимальне напруження припадає на зону згинання, а в зоні формованого борту напруження $€$ малі, У момент інтенсивного фоормування складок напруження зростають і переміщаються із зони згинання в зону складок, утворених на поверхні борту. На останній стадії (рисунок 5), коли складки розгладжуються, напруження розподіляються рівномірно по поверхні борту, а їх максимальне значення після фрормоутворення залишається на нижній крайці борту, що пов'язано із забезпеченням прилягання борту до поверхні матриці.

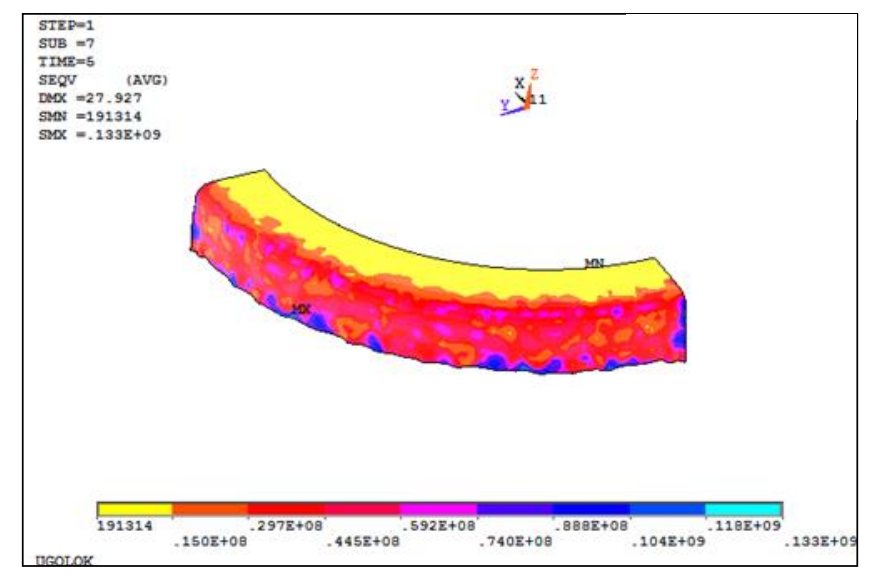

Рис. 5. Схема розподілу напруження на кінцевій стадії формоутворення

Напруження, що виникли, не перевищують напруження, допустимі для цього матеріалу, максимальне їх значення складає 133 МПа. На рисунку 6 показано графрік залежності напруження та інтенсивності напруження від часу фрормоутворення в зоні згинання. Як видно з графіку, напруження спочатку різко зростає, що характеризує початкові стадії фрормоутворення, коли максимум напруження припадає на зону згинання, а надалі відбувається зменшення його величини у зв'язку з початком етапу формоутворення в тангенціальному напрямку. За допомогою графріку можна визначити умовний момент часу, коли починається формоутворення в тангенціальному напрямку, він становить близько 20 \% від загального часу фрормоутворення.

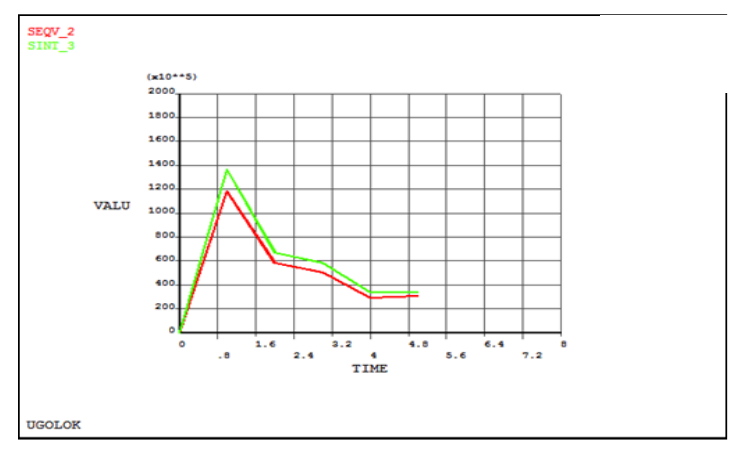

Рис. 6. Графрік залежності напруження і інтенсивності напруження від часу формотворення

За отриманими результатами визначається загальна деформація в заготовці. На рисунку 7 зображено графік залежності сумарної деформації від часу фрормоутворення. 3 графріка видно, що на початкових етапах деформації $\epsilon$ 
незначними, потім настає проміжок різкого збільшення величини дефрормації, що за часом збігається з моментом розпрямлення складок, і на останніх етапах приріст величини деформації знову є незначним.

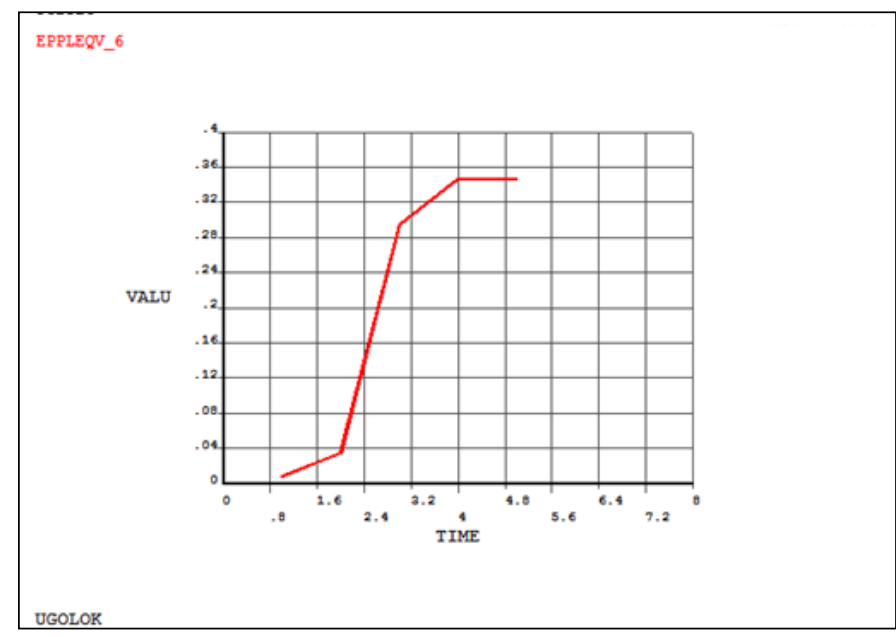

Рис. 7. Граффік залежності приросту величини дефрормації від часу фрормоутворення

За раніше визначеними зонами деталі будується графік еквівалентного напруження рисунок 8). На відміну від попередньої деталі (діафрагми) [1], картина розподілу напруження дещо змінилася. В даному випадку після перетинання зони згинання напруження знижуються потроху, а потім знову зростають на значну величину. Це можна пояснити складною геометрією деталі і процесом складкоутворення, який супроводжує процес фрормоутворення деталі.

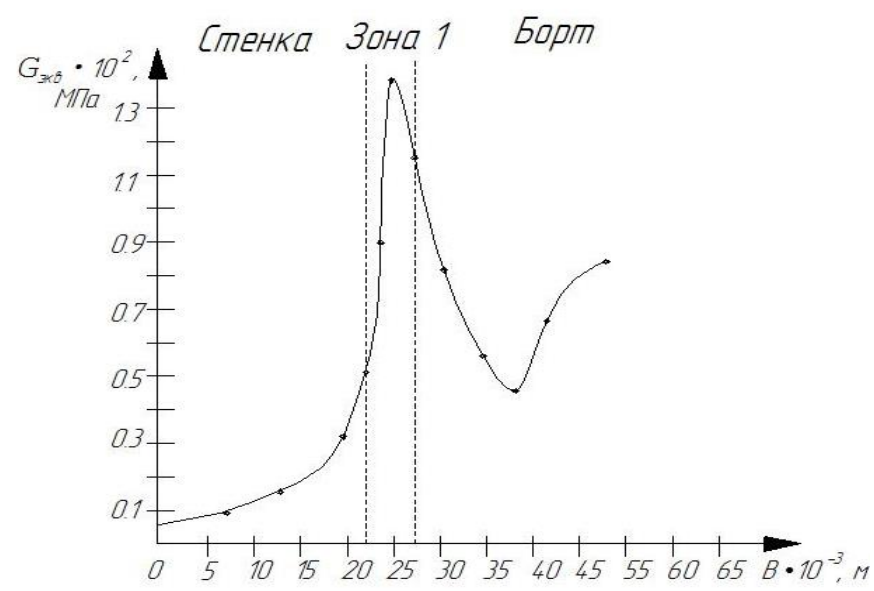

Рис. 8. Величина деформації за зонами деталі

На наступному етапі аналізу було визначено максимально можливі стоншування матеріалу, борти, що виявляються в процесі формування. Вони станвлять $0.06 \cdot 10^{-3}$ м в зоні згинання, що $є$ максимальним значенням. У зоні борту, особливо на нижньому краї і кутових зонах з боків спостерігається потовщення матеріалу, внаслідок розгладження складок. Максимальне 
потовщення становить $0.18 \cdot 10^{-3}$ м. Для визначення величини деформувального тиску для подальших розрахунків необхідно знати величину внутрішнього моменту, який виникає при згинанні заготовки. Максимальне значення становить $150 \boldsymbol{H} \cdot \boldsymbol{m}$.

10. Пружинення. На рисунку 9 показано зміни напруження після розвантаження. Як видно з рисунка, значення напруження рівномірно зменшилися в усіх зонах деталі.

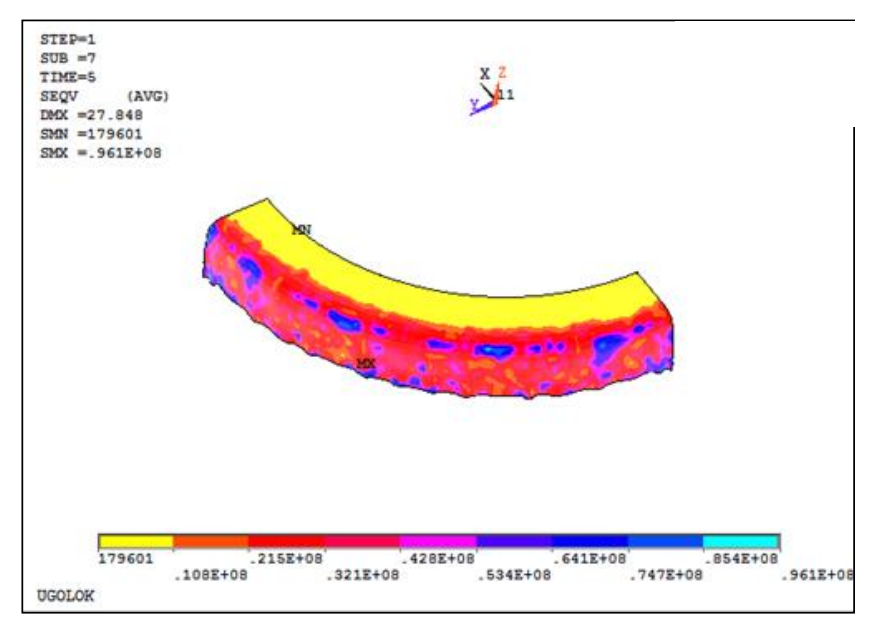

Рис. 9. Розподіл напруження в деталі після розвантаження

Найбільший приріст становить $0.065 \cdot 10^{-3} \boldsymbol{M}$. Враховуючи, що гнуття велося на $90^{\circ}, \sin \varphi=\Delta y, a \quad \varphi=\arcsin (\Delta y)=\arcsin (0.065) \approx 3.58^{\circ}$. Таким чином, корегувальний кут пружинення становить $4^{\circ}$.

На основі проведених досліджень і розрахунків було отримано ряд теоретичних даних про різні технологічні параметри процесу згинанняштампування. Обчислення за спрощеними формулами, які містяться у роботах [3,4,5], дозволило отримати попередні дані за такими параметрами процесу як потрібний для формоутворення тиск, кут пружинения, можливі величини змін товщини заготовки. Проте цей розрахунок не дає повного уявлення про якість отримуваного виробу. Особливо це стосується складних деталей типу опуклого кутника, де відбувається складний процес формоутворення, всі чинники якого можна врахувати лише при проведенні дуже громіздких розрахунків. Побудова математичної моделі на основі MCE дозволяє не лише визначити необхідні параметри процесу, але й розглянути процес фрормозміни на окремих його стадіях, визначити картину напружено-деформованого стану, виявити найбільш небезпечні зони в прцесі згинання-штампування, зміну товщини матеріалу, а також простежити поведінку матеріалу після розвантаження. Bce це дає можливість оцінити якість отримуваного виробу за визначеними параметрами процесу, а також добитися бажаних результатів шляхом варіювання початкових параметрів моделі. Для того, щоб оцінити прийнятність використання такого методу для оцінювання якості деталі і розрахунку потрібних параметрів процесу необхідно визначити збіг результатів, що отримуються при моделюванні, 3 експериментальними даними, тобто оцінити отриману погрішність даних. 
На рисунку 10 показано графрік-схему зміни товщини заготовки в процесі фрормоутворення опуклого кутника. Проте у зв'язку із складністю протікання цього процесу порівняно 3 попереднім, зокрема утворенням складок і стискуванням в тангенціальному напрямку, було розглянуто як зону згинання деталі, так і зону борту. 3 графіку видно, що в зоні борту сталося потовщення матеріалу заготовки. У даному випадку розбіжність отриманих результатів у місцях максимального стоншування і максимального стовщування становить менше 1 \%. Такі дані дозволяють об'єктивно оцінити майбутню якість виробу за критерієм зміни товщини заготовки.

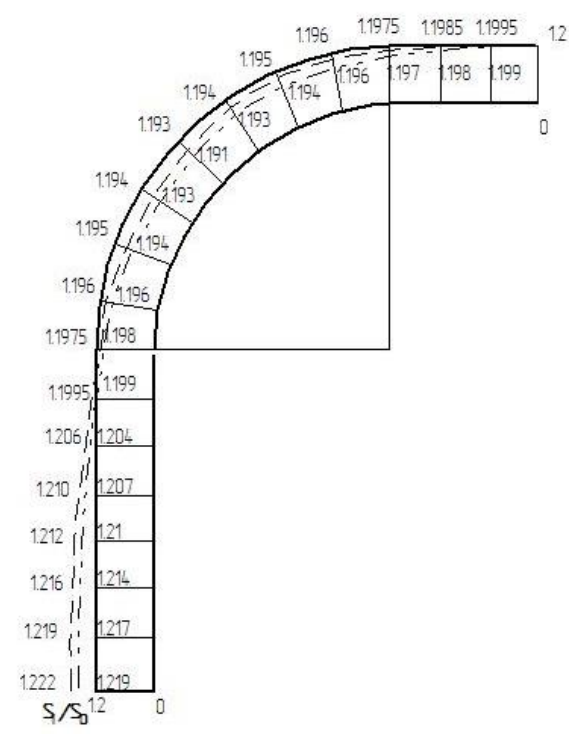

Рис. 10. Графрік-схема зміни товщини заготовкиі для кутника:

значення, отримані при моделюванні; ---.---.---- - експериментальні значення за

Комаровим.

Таким чином, порівняння даних експертименту, розрахунку i моделювання привело до їх розбіжності в середньому на 3 - 5 \% за основними параметрами. Цей результат свідчить про можливість подальшого вдосконалення і застосування моделювання на практиці.

\section{Висновок}

Проведений аналіз отриманих результатів моделювання процесу штампування-згинання опуклого кутника еластичним передавальним середовищем відповідно до результатів експериментів та розрахунків за спрощенними формулами дозволив отримати позитивні відгуки про застосування в подальшому чисельних експериментів з метою забезпечення підвищення якості виготовлення деталей штампуванням 3 листа, значного скорочення обсягів технологічної підготовки штампувальних робіт передавальними середовищами та витрат на її проведення.

\section{Список використаної літератури}

1. Застела, О. М. Моделювання процесу штампування діафрагми згинанням листової заготовки еластичним середовищем / О. М. Застела, О. В. 
Трифонов, В. П. Водолажський // Открытые информационные и компьютерные интегрированные технологии: сб . науч. тр. Нац. аэрокосм. ун-та им.

Н.Е. Жуковского «ХАИ». - Вып. 84. - Харків,2019. - С. 93-109.

2. Hallquist J. O. LS-DYNA theoretitsal manual / J. O. Hallquist. // Livermore Software Technology Tsorporation: Livermore, TsA, 2006. - 498 p.

3. Исаченков, Е. И. Штамповка эластичными и жидкостными середами / Е.И. Исаченко. - М.: Машиностроение, 1976. - 386 с.

4. Комаров, А. Д. Опыт штамповки полиуретаном стальных деталей сложной формы / А. Д. Комаров // КШП: научно-технический журнал. - М.: 1991. - № 8. - С. 11 - 19.

5. Богоявленский К. Н. Изготовление заготовок и деталей пластическим деформированием / К. Н. Богоявленский. - Л.: Политехника, 1991. - 351с.

\section{References}

1. Застела О. М. Моделювання процесу штампування діафрагми згинанням листової заготовки еластичним середовищем / О. М. Застела, О. В. Трифонов, В. П. Водолажський // Открытые информационные и компьютерные интегрированные технологии: сб. науч. тр. Нац. Аэрокосм . ун-та им.

Н.Е. Жуковского «ХАИ». - Вып. 84. - Харків,2019. - С. 93-109.

2. Hallquist J. O. LS-DYNA theoretitsal manual / J. O. Hallquist. Livermore Software Technology Tsorporation: Livermore, TsA, 2006. - 498 p.

3. Y'sachenkov, E. Y'. Shtampovka эlasty 'chnыmy` y' zhy`dkostnыmy` seredamy` / E.Y. Y`sachenko. - M.: Mashy`nostroeny`e, 1976. - 386 s.

4. Komarov, A. D. Opыt shtampovky` poly`uretanom stal`nыx detalej slozhnoj formы / A. D. Komarov // KShP: nauchno-texny`chesky`j zhurnal. - M.: 1991. - \# 8. S. $11-19$.

5. Bogoyavlensky`j K. N. Y`zgotovleny`e zagotovok y` detalej plasty`chesky`m deformy`rovany`em / K. N. Bogoyavlensky`j. - L.: Poly`texny`ka, 1991. - 351s.

\section{Modeling the Stamping Process of a Convex Corner Flexion-Forming a Transmitting Noedium}

Computer simulation allows you to monitor the load of material and its behavior in the course of molds, to determine the energy parameters of the process, to reflect the kinematics of the tool movement, the transmitting agent and the workpiece itself. This provides a significant reduction in time and expenses for natural experiments, in general, a significant decrease in the volumes of technological preparation of stamping works. The indicated method is most suitable for improving modern stamping production using transmitting environments. For numerical experiments in the punching region of billets from the sheet, the most acceptable variational method or ICE is the most acceptable. This approach provides minimal discrepancy between the results of natural and numerical experiments. Its is widely used in various programmates Nastran, Ansys, Katy, etc., which allows you to optimize the process of receiving data reduction in time, quickly edit to all sorts of changes on deformation conditions. During the process of shaping the convex corner there are significant changes in geometry related to corrugated formation on the 
collateral part of the workpiece. For this reason, the approach to the formation of a mesh sampling for the MSE calculations have the features of methods of use in the size of the breakdown elements, in particular for the transmitting medium and the leaf workpiece, the size of the elements small, and for equipping can be selected large, except the flexible surface. The construction of the mathematical model based on the ITS allows not only to determine the necessary parameters of the process, but also to consider the process of shapes in individual stages, to determine the painting of a stress-deformed state, to identify the most dangerous zones of bending-stamping, changing the thickness of the material, and trace the behavior of the material after unloading . All this makes it possible to evaluate the quality of the resulting product according to the specified parameters of the process, as well as the desired results by varying the initial parameters of the model.

Keywords: modeling of the stamping process, sheet workpiece, convex bending, forming, transmitting medium.

\section{Відомості про авторів:}

Застела Олександр Миколайович - к.т.н., доцент, професор кафедри технології виробництва літальних апаратів, Національний аерокосмічний університет ім. М.Є. Жуковського «Харківський авіаційний інститут», Харків, Україна, sastela@khai.edu

\section{About the Authors:}

Zastela Oleksandr - PhD, Professor Assistant, Professor of the Airplane Manufacturing Department, National Aerospace University named after M. Ye. Zhukovsky "Kharkiv Aviation Institute", Kharkiv, Ukraine, sastela@khai.edu 